\title{
O conhecimento de jovens universitários sobre AI DS e sua prevenção
}

\section{Young academic knowledge about aids and its prevention}

\section{El conocimiento de los jóvenes universitarios sobre sida y su prevención}

\author{
Maria Aparecida Tedeschi Cano', J osé Eduardo Zaia', Fátima Regina Almeida Neves"', Lis Aparecida \\ Souza Neves ${ }^{\prime \prime \prime}$
}

\section{RESUMO}

A Aids é um grave problema de Saúde Pública, pois a cada ano aumenta o número daqueles que se contaminam. No Brasil a transmissão heterossexual tornou-se a principal via de contágio do HIV. Objetivo: levantar junto a jovens de 17 a 24 anos que cursam o terceiro grau, os conhecimentos sobre a Aids e sua prevenção. Metodologia:pesquisa desenvolvida em uma universidade privada do interior do estado de São Paulo, com alunos de ambos os sexos dos cursos de Pedagogia, Jornalismo, Moda e Turismo. Foi aplicados 300 questionários com perguntas abertas e fechadas no período de fevereiro a abril de 2006. Resultados: 95\% dos alunos conhecem a doença e o modo de transmissão; $66 \%$ disseram usar o preservativo masculino e $26 \%$ não ou depende e o motivo alegado é parceiro fixo, casamento, confiança no parceiro. Quanto à dificuldade para usar o preservativo $60 \%$ disseram não ter nenhuma, mas, 50 \% relatam dificuldades como: colocação, perda de sensibilidade, entre outros. Apenas 2\% dos alunos já usaram o preservativo feminino. Para $57 \%$ dos entrevistados, a palavra Aids lembra morte, sofrimento e dor.

Palavras chave: Promoção da saúde; Prevenção de doenças transmissíveis; Síndrome de Imunodeficiência Adquirida; Preservativos.

\section{ABSTRACT}

Aids is a serious problem of Public Health, because each year rises the number of contaminated persons. In Brazil, heterosexual transmission became the main way of infection by HIV. Goal: to know, how adolescents, in the age-group of 17 to 24 years old that attend to the third degree school pattern, know about Aids and its prevention. This research was developed on a private university in the state of São Paulo, Brazil, interviewing students, from courses: journalism, fashion, tourism pedagogy. We applied 300 questionnaires with openned and closed questions in the period from february to april of 2006. Results: $95 \%$ of students has a knowledge of Aids and the way of its transmission. As for the use of preservatives, $66 \%$ said they use them and $26 \%$ do not use them and the alleged motive are: stable partner, marriage. As for to the difficulty to use preservatives $60 \%$ said they have no problems, but $50 \%$ reported difficulties to put them on, lost of sensibility, tightness, among others. Only $2 \%$ of students used the feminine preservatives. To $57 \%$ of the interviewed students, the word Aids remembers death, suffering and pain.

Key words: Health promotion; Prevention of transmissible diseases; Acquired immune deficiency syndrome; Preservative.

\section{RESUMEN}

SIDA es un grave problema de Salud Pública, pues a cada año aumenta el número de aquellos que se contaminan. En Brasil la transmisión heterosexual es la principal forma de contagio del HIV. Aunque haya muchas campañas enfatizando la prevención de SIDA, el número de jóvenes e especialmente de mujeres sigue aumentando. Objetivo: fue relevar junto a jóvenes de 17 a 24 años que cursan el tercer grado, los conocimientos sobre SIDA y su prevención. La investigación fue desarrollada en una universidad particular del interior del estado de São Paulo, con alumnos de ambos los sexos de los cursos de Periodismo, Moda, Turismo, Pedagogía. Fueron aplicados 300 cuestionarios con preguntas abiertas y cerradas en el período de febrero a

\footnotetext{
'Doutor. Docente orientador de curso de Pós-Graduação em Promoção de Saúde da Universidade de Franca UNIFRAN - São Paulo.

" Mestre. Coordenadora do Programa de DST/ AIDS da Secretaria Municipal de Saúde de Ribeirão Preto/SP

III Mestre. Enfermeira do Programa de DST/ AIDS da Secretaria Municipal de Saúde de Ribeirão Preto/SP
} 
Cano MAT, Zaia JE, Neves FRA, Neves LAS. O conhecimento de jovens universitários sobre AIDS e sua prevenção. Revista Eletrônica de Enfermagem [serial on line] 2007 Set-Dez; 9(3): 748-758. Available from: URL: http://www.fen.ufg. br/revista/v9/n3/v9n3a14.htm

abril de 2006. Resultados: $95 \%$ de los alumnos conocen la enfermedad y el modo de transmisión. Cuanto a usar el preservativo, $66 \%$ dicen que sí y $26 \%$ no o depende, siendo los motivos pareja fija, matrimonio. Cuanto a la dificultad para usar el preservativo, $60 \%$ dijeron no tener ninguna, pero $50 \%$ relatan dificultades: colocación, pérdida de sensibilidad, entre otros. Apenas $2 \%$ de los

\section{NTRODUÇÃO}

A Síndrome da Imunodeficiência Adquirida - AIDS é uma doença infecciosa causada por um vírus, denominado HIV. Está presente em células sanguíneas, principalmente nos linfócitos $\mathrm{T}(\mathrm{CD} 4+)$ e macrófagos, o que permite sua transmissão, através do sangue, esperma, líquidos vaginais, leite materno.

A AIDS é a manifestação clínica da infecção pelo HIV que leva, em média, de oito a dez anos para se manifestar. No Brasil, desde a identificação do primeiro caso de em 1980, até junho de 2005, já foram notificados, cerca de 372 mil casos da doença ${ }^{(1)}$.

Em muitas partes do mundo em desenvolvimento, a maioria dos casos de infecção ocorre em adultos jovens. Cerca de $1 / 3$ dos que vivem atualmente com HIV/AIDS têm entre 15 a 24 anos e não sabem que são portadores do vírus desconhecendo formas de se proteger e prevenir o contágio e a transmissão (2). Atualmente sabe-se que a transmissão heterossexual da AIDS tornou-se a principal via de contágio do HIV no Brasil ${ }^{(3)}$.

$\mathrm{O}$ vírus HIV está em leucócitos presentes no sêmen, que os possui para defender os órgãos genitais de outros agentes patogênicos. O HIV pode ser transmitido por micro ferimentos no pênis e na vagina que podem surgir durante $o$ ato sexual. $O$ não uso de alumnos ya usaron el preservativo femenino. Para $57 \%$ la palabra SIDA significa muerte, sufrimiento y dolor.

Palabras clave: Promoción de salud; Prevención de enfermedades transmisibles; Síndrome de inmunodeficiencia adquirida; Preservativo.

preservativo é uma das principais causas da transmissão do vírus por contato sexual ${ }^{(2)}$.

Vale ressaltar que tanto no Brasil, como na América Latina, a AIDS é cada vez, mais feminina, mais jovem e pobre. A Síndrome afeta cada vez mais mulheres que adquirem o vírus em suas próprias casas através dos maridos ou companheiros. No começo da epidemia haviam 20 homens infectados para cada mulher. Quase duas décadas depois, a propagação registrada é praticamente de 1 (um) homem para cada mulher infectada ${ }^{(4)}$.

Existe uma desigualdade sexual entre homem e mulheres dos países em desenvolvimento, onde também existe marcada desigualdade de gênero em instâncias diversas da sociedade, não apenas nas relacionadas à AIDS, submetendo mulheres, crianças e adolescentes a múltiplos riscos como violência sexual e dependência econômica ${ }^{(5)}$.

A combinação destes e outros fatores e da "dupla moral" no que diz respeito ao comportamento sexual de homens e mulheres no âmbito da sociedade e da família, faz com que seja mais difícil para as mulheres ter acesso a informação adequada sobre HIV/AIDS e, uma vez tendo essas informações, modificar comportamentos ${ }^{(5)}$.

No Brasil, do total de casos de AIDS mais de $80 \%$ concentram-se na região sudeste e 
Cano MAT, Zaia JE, Neves FRA, Neves LAS. O conhecimento de jovens universitários sobre AIDS e sua prevenção. Revista Eletrônica de Enfermagem [serial on line] 2007 Set-Dez; 9(3): 748-758. Available from: URL: http://www.fen.ufg. br/revista/v9/n3/v9n3a14.htm

sul. O sudeste é a região mais atingida desde o início da epidemia ${ }^{(1)}$.

Ao contrário do que se pensou no início da década de 80 , a infecção pelo HIV, não se limita à identidade sexual, mas a comportamentos adotados. Apesar de muito se ter evoluído em relação à prevenção, assistência e pesquisa, esforços ainda devem ser centrados com vistas a conter a infecção pelo HIV e consequentemente a AIDS ${ }^{(6)}$. A epidemia que iniciou entre indivíduos homossexuais masculinos, passou pelos hemotransfundidos, pelos usuários de drogas injetáveis e, nos últimos anos, tem apresentado como principal categoria de exposição, a via sexual.

Em pesquisa realizada no Brasil, verificou-se que $91 \%$ da população brasileira de 15 a 54 anos citaram, a relação sexual como forma de transmissão do HIV e 94\% citaram o uso do preservativo como forma de prevenção da infecção ${ }^{(7)}$.

A pesquisa mostra que apesar do conhecimento sobre o HIV/AIDS e a forma de transmissão, o uso do preservativo ainda é baixo, aproximadamente $38 \%$ da população entrevistada e sexualmente ativa usou o preservativo na última relação sexual, independente da parceria.

Diante destes dados considera-se que seria importante conhecer o que pensam os alunos do 30 grau de uma universidade privada, pertencentes a uma classe social com maior informação sobre HIV/AIDS e sua prevenção.

A princípio, espera-se que os jovens estejam se protegendo. Caso não estejam, acredita-se poder identificar qual o motivo ou dificuldade encontrada, para posteriormente se planejar intervenções de educação em saúde que sejam capazes de auxiliar essa população a ter mais responsabilidade para consigo e com os seus semelhantes.

Para tanto, essa pesquisa tem como objetivo levantar junto a jovens e adolescentes de 17 a 24 anos que cursam o terceiro grau, os conhecimentos adquiridos sobre a AIDS e se estes utilizam alguma forma de prevenção.

\section{METODOLOGI A}

Este é um estudo do tipo descritivo, realizado no período de fevereiro a abril de 2006, em uma universidade privada do interior do estado de São Paulo, com estudantes universitários matriculados nos cursos de moda, turismo, publicidade, jornalismo e pedagogia, cujas grades curriculares não possuíam nenhuma disciplina da área da saúde.

A pesquisa foi aprovada pelo Comitê de Ética em Pesquisa da Universidade de Franca, sob o número 017/06. A participação dos universitários foi voluntária, após a assinatura do Termo de Consentimento Livre e Esclarecido.

Para participar da pesquisa o aluno deveria estar regularmente matriculado em um dos referidos cursos, naquele ano letivo, estar na faixa etária de 17 a 24 anos e presente na sala de aula no dia da pesquisa.

Os dados foram obtidos por meio de um questionário semi-estruturado, autopreenchível, anônimo, contendo perguntas relacionadas à AIDS como: significado do termo; modos de transmissão; uso de preservativos nos relacionamentos sexuais; conhecimento sobre o preservativo feminino; 
Cano MAT, Zaia JE, Neves FRA, Neves LAS. O conhecimento de jovens universitários sobre AIDS e sua prevenção. Revista Eletrônica de Enfermagem [serial on line] 2007 Set-Dez; 9(3): 748-758. Available from: URL: http://www.fen.ufg. br/revista/v9/n3/v9n3a14.htm

dificuldades para o uso dos preservativos; sugestões sobre formas de prevenção.

Os questionários foram respondidos em sala de aula, após explanação pelo pesquisador sobre os objetivos e a natureza da pesquisa.

O questionário foi aplicado a uma amostra estratificada por cursos. A população destes cursos é constituída por aproximadamente 3.000 alunos e a amostra foi dimensionada em 300 alunos, para um grau de significância igual a 95\%, com margem de erro de $5,4 \%$.

A análise e discussão dos dados foram realizadas através de agrupamentos, de forma a contemplar os itens contidos no questionário, confrontando-os com os princípios da literatura, na tentativa de descrever e explorar os aspectos de cada situação.

\section{RESULTADOS}

A amostra deste estudo foi composta de 300 adolescentes e adultos jovens de ambos os sexos, sendo 90 masculinos e 210 do sexo feminino. Esta diferença de sexos se deve ao fato de nos cursos citados haver uma maior porcentagem $(60 \%)$ de mulheres matriculadas.

$\mathrm{Na}$ análise das respostas as questões 2 e 3 do questionário relacionadas ao conhecimento sobre HIV/AIDS e vias de transmissão, verificou-se que $92 \%$ dos entrevistados sabem que a doença tem como agente etiológico um vírus e 95\% que ele é sexualmente transmissível como se pode observar no Gráfico 1.

Gráfico 1: Distribuição das respostas de acordo com o conhecimento sobre HIV/AIDS. Franca-SP, 2006.

Lembram do coquetel

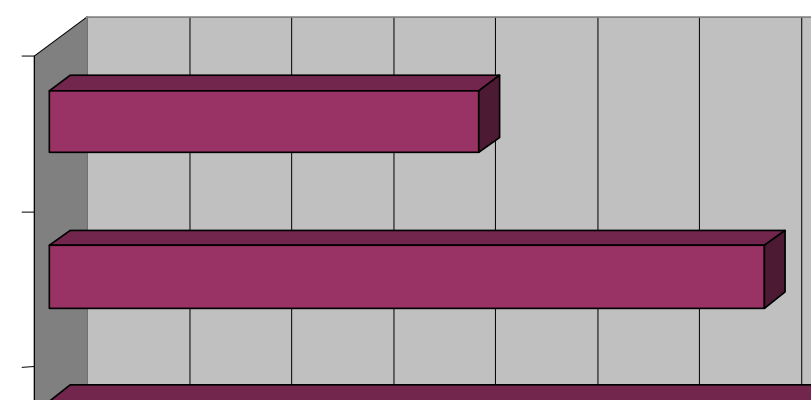

Não tem cura

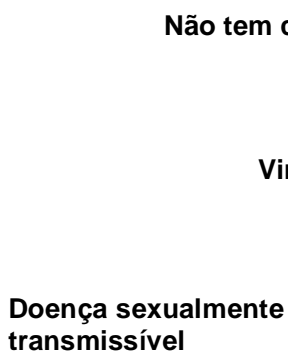

Virus

transmissível

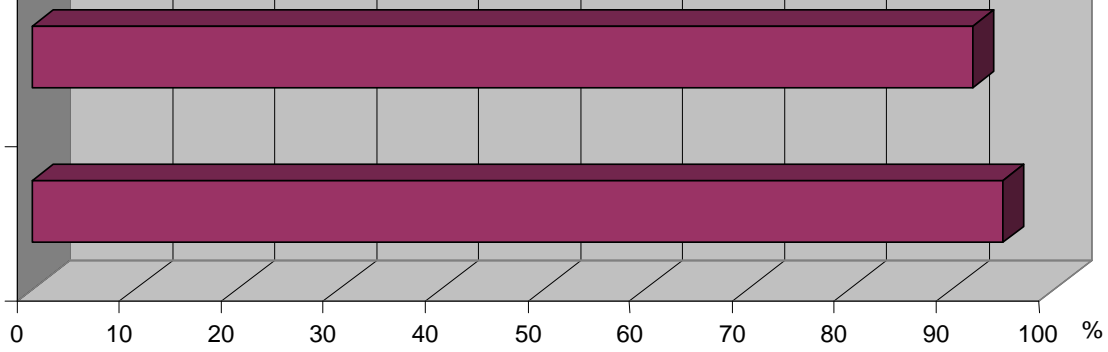

Esses dados apontam que estes jovens têm conhecimentos sobre 0 HIV/AIDS compatível com seu grau de instrução. No início da epidemia, na sua identificação, a AIDS era uma doença que atingia principalmente homossexuais masculinos. Na atualidade, esse padrão mudou, deixando a transmissão sexual heterossexual como responsável por $80 \%$ dos casos e atingindo, sobretudo as mulheres ${ }^{(6)}$. 
Cano MAT, Zaia JE, Neves FRA, Neves LAS. O conhecimento de jovens universitários sobre AIDS e sua prevenção. Revista Eletrônica de Enfermagem [serial on line] 2007 Set-Dez; 9(3): 748-758. Available from: URL: http://www.fen.ufg. br/revista/v9/n3/v9n3a14.htm

Em estudo nacional sobre o conhecimento da população adulta sobre a infeç̧ão pelo HIV (8) é apontado que $91 \%$ citaram a relação sexual como forma de transmissão. Neste estudo, com relação à via transmissão, 90\% dos entrevistados citaram as drogas injetáveis e $84 \%$ o sangue como veículo de transmissão, sendo que as secreções sexuais aparecem em $67 \%$ das respostas e $22 \%$ acreditam que o vírus esteja presente na saliva ${ }^{\left({ }^{(8)}\right.}$. Estes dados estão apontados no Gráfico 2.

Gráfico 2: Distribuiçã̃o das respostas de acordo com o conhecimento sobre as vias de transmissão. Franca-SP, 2006.

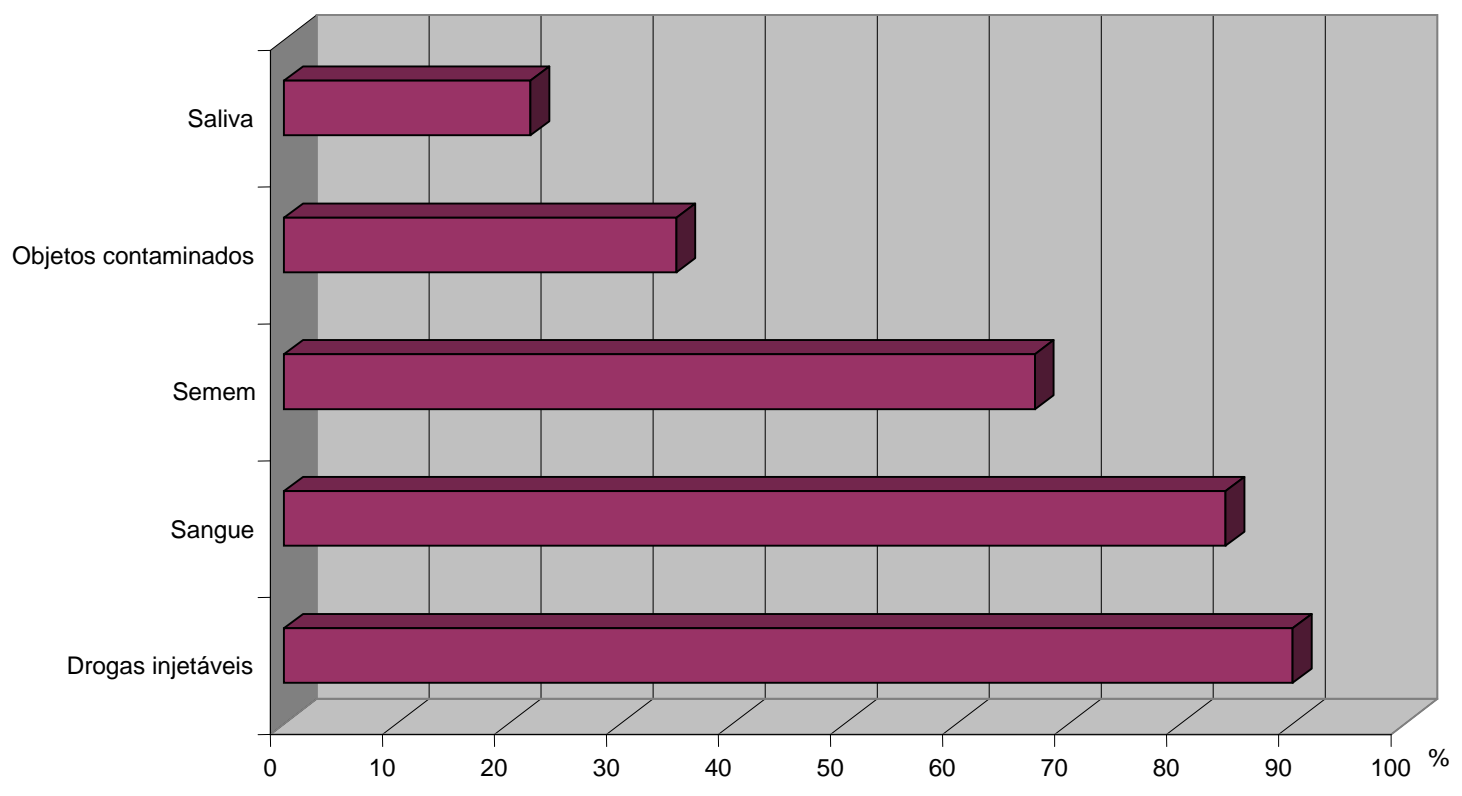

A contaminação sanguínea ocorre principalmente por compartilhamento de seringas contaminadas com sangue entre usuários de drogas injetáveis. No Brasil essa via de contaminação responde por $18 \%$ da incidência de casos de AIDS ${ }^{(2)}$.

Com relação à contaminação pelo vírus através da hemoterapia houve uma redução por essa via, graças ao desenvolvimento e adoção de novas tecnologias objetivando minimizar os riscos transfusionais ${ }^{(9)}$.

Embora a transmissão vertical não tenha sido citada pelos jovens da pesquisa, estima-se que entre 15 a $30 \%$ das crianças nascidas de mães soropositivas para $\mathrm{O}$ HIV podem ter adquirido o vírus na gestação, durante o trabalho de parto ou por meio da amamentação. Porém, o uso combinado de determinadas intervenções pode reduzir essas taxas para cifras inferiores a $2 \%{ }^{(10)}$.

Por outro lado, ainda que esteja cientificamente provado que o vírus da AIDS não é transmissível pelo ar, insetos, nem pela saliva, os preconceitos continuam vigentes, inclusive entre os próprios profissionais de saúde ${ }^{(4)}$.

No que se refere à questão 4 do questionário: "Quando você ouve falar a palavra AIDS, do que você lembra?" verificouse que $57 \%$ dos entrevistados referiram-se à 
Cano MAT, Zaia JE, Neves FRA, Neves LAS. O conhecimento de jovens universitários sobre AIDS e sua prevenção. Revista Eletrônica de Enfermagem [serial on line] 2007 Set-Dez; 9(3): 748-758. Available from: URL: http://www.fen.ufg. br/revista/v9/n3/v9n3a14.htm

morte, doença incurável, sofrimento e dor. Esses dados mostram que ainda o medo ronda o imaginário de jovens e da população, que se acostumou a ver na imprensa, em filmes e em reportagens da mídia indivíduos, muito jovens, magros, pele macilenta, olhos encovados, sem cabelos, afastados do convívio social e do trabalho, tanto por questões físicas, como geradas pelo preconceito e a discriminação.

Apesar da evolução no tratamento da AIDS que aumentou a sobrevida do paciente, nas representações populares a associação entre AIDS e morte é muito presente ${ }^{(11)}$.

O significado da AIDS foi construído socialmente baseado no medo, no estigma, no preconceito. No medo, quando algumas frases referentes à AIDS se tornaram slogan de campanhas: "A AIDS mata"; "se você não se cuidar a AIDS vai te pegar", veiculadas diariamente na mídia, em outdoors espalhados pelas cidades ${ }^{(12)}$.

Esse medo tende a desaparecer com o tempo, principalmente devido ao uso de medicamentos anti-retrovirais, o conhecido "coquetel", que tem provocado melhoras na qualidade de vida dos portadores do HIV/AIDS e mudado a imagem desses indivíduos debilitados físico e emocionalmente.

No entanto, o estigma e o preconceito ainda permanecem no imaginário da sociedade. No início da epidemia os portadores de HIV/AIDS eram relacionados como vítimas, no caso dos infectados por hemoderivados, ou como culpados, no caso dos homossexuais, prostitutas e usuários de drogas. Vistos como promíscuos era atribuída a eles a responsabilidade pela infecção ${ }^{(13)}$.

Embora tenham ocorrido mudanças ao longo de 25 anos de epidemia, ainda hoje o estigma e o preconceito estão presentes na sociedade. Os conceitos de grupo de risco permanecem no imaginário social, contribuindo para que a AIDS seja vista como a doença do outro e dando a falsa sensação de distância do perigo ${ }^{(11)}$.

A crença inicial de que a AIDS seria uma doença circunscrita a determinados "grupos de risco" continua sendo um dos empecilhos para a prevenção em mulheres que imaginam que "só os outros podem contrair o HIV". A racionalização falseadora está intimamente relacionada ao fato de que as informações sobre AIDS foram, durante muito tempo na história da epidemia, transmitidas com a idéia da existência de grupos de risco, que se referiam a indivíduos muito estigmatizados (promíscuos, viciados, pervertidos). Ninguém quer se identificar com esses indivíduos sob risco ${ }^{(14)}$.

As pesquisas e o avanço científico e tecnológico desenvolvem medicamentos cada vez mais eficazes que possibilitam aos portadores do vírus sobrevida cada vez maior e com melhor qualidade. Hoje a AIDS pode ser considerada uma doença crônica e a pessoa infectada pode viver com vírus por longos períodos, sem apresentar sintomas ${ }^{(15)}$.

No período anterior ao advento da terapia anti-retroviral os portadores de HIV/AIDS necessitavam de longos períodos de internação hospitalar, mas, atualmente dispõe da possibilidade de continuarem seu tratamento em ambulatórios ${ }^{(14)}$.

Tanto este fato é realidade que dentre os entrevistados dessa pesquisa, encontrou-se uma resposta que sinalizava "Conheço um vizinho que é 'aidético' e que está muito bem". Vale ressaltar que apesar do grande avanço 
Cano MAT, Zaia JE, Neves FRA, Neves LAS. O conhecimento de jovens universitários sobre AIDS e sua prevenção. Revista Eletrônica de Enfermagem [serial on line] 2007 Set-Dez; 9(3): 748-758. Available from: URL: http://www.fen.ufg. br/revista/v9/n3/v9n3a14.htm

alcançado com a medicação, o indivíduo que faz uso dela necessita de grande empenho pessoal, pois a quantidade de comprimidos diários é alta, podem surgir intolerâncias gástricas e a medicação é para ser usada o resto da vida, já que atualmente a AIDS ainda não tem cura. Existe a necessidade de adaptação da vida domiciliar a esta nova rotina e aos efeitos adversos dos medicamentos ${ }^{(14)}$.

A outra metade dos entrevistados fez referências mais voltadas para a prevenção da doença, a falta de cuidados e o uso do preservativo. Esses dados são apresentados no Gráfico 3.

Gráfico 3 - Distribuição das respostas de acordo com a lembrança sobre AIDS. Franca-SP, 2006.

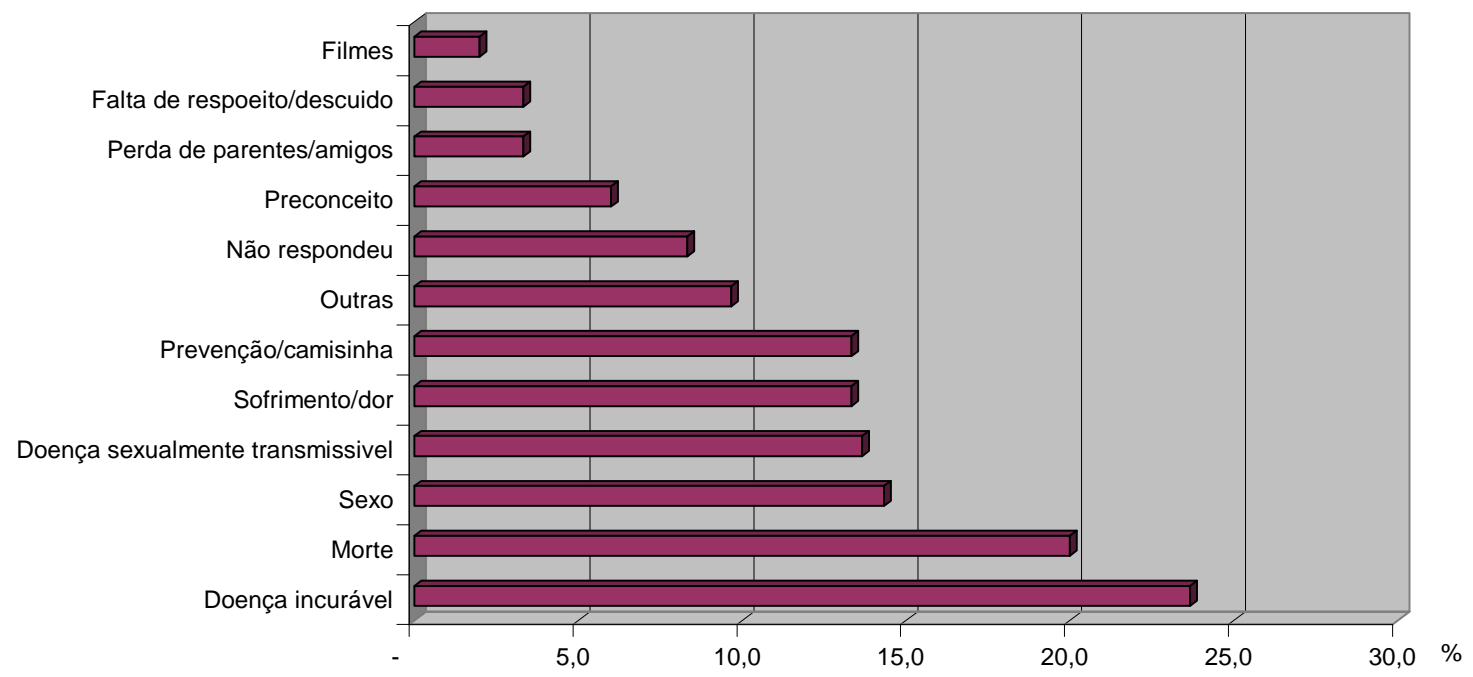

Com relação ao uso do preservativo, verifica-se que $66,3 \%$ dos entrevistados fazem uso; o restante disse que "não", "às vezes" ou não responderam. As justificativas para o não uso do preservativo foram: "quando você já conhece o parceiro"; "quando você é casada" ou "quando tem parceiro fixo", "porque sou evangélico e sexo só no casamento".

Percebe-se que apesar de toda a informação já veiculada sobre a AIDS, mesmo aquelas que amedrontam; o conhecimento adquirido sobre o vírus e o modo de transmissão ainda não permitiram aos jovens uma mudança de comportamento para o uso do preservativo.

Aumentar o nível de informação sobre as vias de transmissão do HIV e sobre a necessidade de usar o preservativo não garante mudanças comportamentais, o que indica a necessidade dos programas preventivos contemplarem o contexto psicossocial do indivíduo e as diferenças de gênero ${ }^{(16)}$.

A reportagem da revista Veja, edição especial, "J ovens", coloca que "nunca os jovens foram tão bem informados sobre sexo. Mas nem sempre eles levam a teoria à prática". $\mathrm{Na}$ reportagem, o psiquiatra Jairo Bauer aponta que os jovens não conseguem processar toda a massa de informações, ou seja, que a informação nem sempre se traduz necessariamente numa prática mais cuidadosa (17). 
Cano MAT, Zaia JE, Neves FRA, Neves LAS. O conhecimento de jovens universitários sobre AIDS e sua prevenção. Revista Eletrônica de Enfermagem [serial on line] 2007 Set-Dez; 9(3): 748-758. Available from: URL: http://www.fen.ufg. br/revista/v9/n3/v9n3al4.htm

Por outro lado, fica extremamente difícil e subjetiva a informação relativa ao parceiro fixo ou estável pelos jovens nesta fase da vida e por isso há risco de se contrair o HIV. Uma atitude que deveria ser orientada pelos profissionais de saúde e educação aos jovens é o diálogo entre os parceiros, esta atitude é fundamental para a preservação da saúde sexual ${ }^{(12)}$.

Ressalta-se ainda, que a AIDS em mulheres é cada vez mais importante, dado o crescimento da infecção nesta população. Considerando que na amostra do presente estudo esse é o maior grupo identifica-se aqui um problema que merece atenção. A OMS (Organização Mundial de Saúde) estima que, mundialmente 35 milhões de mulheres, estejam contaminadas pelo HIV, em idade reprodutiva e esta situação tem repercussões não apenas individuais, mas também para a família e sociedade, dado o importante papel feminino de mãe e educadora (12).

As mulheres têm consciência de sua vulnerabilidade, mas sabem que tem poder limitado para reduzir ou eliminar o risco em suas relações sexuais. Os homens não querem usar o preservativo e não o farão, as mulheres, por sua vez, não arriscarão sua estabilidade econômica, relações afetivas e nem enfrentarão a violência que um confronto deste tipo pode gerar ${ }^{(18)}$.

$\mathrm{Na}$ transmissão sexual do HIV as relações de gênero, ou seja, um comportamento construído socialmente e marcado pela cultura para definir atitudes de homem e mulher, torna ambos mais frágeis e vulneráveis. Enquanto o que é culturalmente aceitável sinaliza uma cobrança de que o homem tenha que ser viril, a mulher tem que ser submissa, cria-se um contexto social que dificulta a negociação do sexo seguro, tornando-as mais vulneráveis à infecção pelo HIV ${ }^{(11)}$.

Apesar das mulheres terem informação e conhecerem os riscos, elas não usam o preservativo em relacionamento estável devido à ausência de poder de decisão, pelas relações desiguais de gênero e pelas questões relacionadas à fidelidade conjugal ${ }^{(19)}$.

A convivência prolongada deixa a mulher com o sentimento de que está imune, e a confiança no companheiro, base das relações amorosas, não leva em consideração a vida pregressa dele. A fidelidade e a situação conjugal aparecem como imunização contra a infecção; a convivência com alguém que se ama e a confiança no parceiro são fatores facilitadores da negação do risco.

Desta forma, embora se diga que hoje em dia homens e mulheres têm direitos iguais, percebe-se que na prática do relacionamento sexual não é isso o que acontece, principalmente quanto ao uso da "camisinha" aumentando a vulnerabilidade feminina.

Percebe-se esta realidade em algumas respostas ao questionário, onde algumas das entrevistadas colocam: "não sei o que meu parceiro pode pensar", "o parceiro recusa". Continua existindo uma desigualdade sexual entre homens e mulheres para propor o uso da camisinha. Porque ou se considera de um lado que ela trai o marido ou companheiro, ou porque simplesmente ele se recusa a usá-la ${ }^{(4)}$.

A confiança e a fidelidade são as principais razões para que o casal não use preservativo enquanto método preventivo das infecções sexualmente transmissíveis (IST) e AIDS. Quando o casal convive há muitos anos, criam-se vínculos de confiança que determinam 
Cano MAT, Zaia JE, Neves FRA, Neves LAS. O conhecimento de jovens universitários sobre AIDS e sua prevenção. Revista Eletrônica de Enfermagem [serial on line] 2007 Set-Dez; 9(3): 748-758. Available from: URL: http://www.fen.ufg. br/revista/v9/n3/v9n3a14.htm

um comportamento típico de relação monogâmica, que implica na fidelidade da parceria, sem necessidade de prevenção das $\mathrm{IST}^{(20)}$. A prevenção se introduz como uma proposta de mudança no vínculo do casal, alterando o nível de confiança e de contrato. Este fato sendo inserido no imaginário romântico que perpassa o gênero feminino e seus valores, explica o aumento do número de casos do HIV/AIDS entre mulheres casadas ${ }^{(20)}$.

Quanto à questão 6, que abordava "Você conhece o preservativo feminino? Já o usou em seus relacionamentos? Verificou-se que $63,6 \%$ dos entrevistados já ouviram falar ou já viram um preservativo feminino, mas apenas 1,6\% já o usaram em seus relacionamentos. Entre os que já usaram, apareceram algumas respostas como: "é muito caro", "fica antiestético", ou "senti dificuldade em colocar". Com relação a esta última fala, sabe-se que culturalmente as mulheres latino-americanas, não foram educadas para conhecer o próprio corpo, ou se tocar, daí a dificuldade em se aderir à prevenção, através desse preservativo.

Além dos fatores de aumento da suscetibilidade feminina com a AIDS, uma outra questão que se evidencia diz respeito à pequena disponibilidade de métodos de prevenção controlados pelas mulheres como é o caso do preservativo feminino. Infelizmente este é ainda restrito basicamente às camadas mais ricas das sociedades, com maior informação e em contextos culturais mais receptivos à inovação e a iniciativa ${ }^{(5)}$.

$\mathrm{Na}$ questão 7, “Aponte as dificuldades para usar o preservativo", verificou-se que $62,6 \%$ dos entrevistados disseram não ter nenhuma dificuldade para o seu uso, as demais respostas apontam alguma dificuldade, como no caso de alergias, onde 3,3\% não conseguem ou usam o preservativo com dificuldade. Algumas situações referem-se à falha de domínio na hora de colocar o preservativo, ou porque não sabe de fato colocá-lo, ou porque a ansiedade atrapalha, ou ainda pelo medo de que ele estoure.

Um outro grupo de entrevistados que representa $11,6 \%$ das respostas, referem que - uso do preservativo incomoda, provoca desconforto ou aperta. Para $19,6 \%$ dos jovens, o preservativo tira a sensibilidade, faz a relação ficar artificial, interfere negativamente no clima da relação.

O argumento masculino da perda de sensibilidade para o prazer sexual e a associação do uso do preservativo às DST e às relações casuais fora de casa, contribuem para sua rejeição. A recusa do uso do preservativo acontece com mais freqüência nas relações sexuais dos homens com suas parceiras estáveis ou esposas. O controle do comportamento sexual e da fidelidade da parceira estável também implica em associar o uso da camisinha às relações com prostitutas (18)

Considerando que essa seja uma problemática que mostra a dificuldade das pessoas em utilizarem métodos de proteção, talvez parte dela esteja relacionada à forma com que os profissionais de saúde abordam os interessados. Tendo em vista que são eles, as pessoas diretamente envolvidas na discussão da questão do uso do preservativo, possivelmente tenham dificuldade em tornar clara a mensagem, por uma questão de inibição, ou dificuldade em abordar o tema sexualidade. 
Cano MAT, Zaia JE, Neves FRA, Neves LAS. O conhecimento de jovens universitários sobre AIDS e sua prevenção. Revista Eletrônica de Enfermagem [serial on line] 2007 Set-Dez; 9(3): 748-758. Available from: URL: http://www.fen.ufg. br/revista/v9/n3/v9n3a14.htm

A formação insatisfatória nas universidades, que são organismos de formação por excelência, tem como conseqüência a falta de informação oferecida pelos profissionais de saúde à população assistida. Significa, portanto, dizer que um profissional de saúde, para lidar com temas como a sexualidade, precisaria dispor de formação específica nessa área, ainda durante a graduação ${ }^{(12)}$.

Para a questão 8 , onde solicitou-se sugestões à respeito de formas de prevenção da AIDS, obteve-se mais de 300 respostas, haja visto que um sujeito apresentou mais de uma sugestão. Muitas sugestões se referem à importância de disponibilizar palestras nas Universidades, distribuição de panfletos e camisinhas, não apenas em períodos específicos como o carnaval, mas durante todo o ano. Sugestões de cunho religioso; de ajudar pais no diálogo com os filhos; de introduzir educação sexual nas primeiras séries do ensino, antes da criança começar uma vida sexual, entre outras, também foram freqüentes.

Algumas sugestões, entretanto chamaram a atenção, como: "Campanhas mais voltadas para "o sexo divertido" e não seguro". O seguro no geral está associado à falta de prazer, ou "buscar parcerias com cursos de Marketing, para bolar formas de incentivar os jovens a usar preservativo".

A epidemia da AIDS constitui um dos mais graves problemas de saúde pública da atualidade, transcendendo as ações de um Programa de Prevenção e Assistência às DST/AIDS. Existem facetas sócio-econômicas e culturais arraigadas e difíceis de serem transpostas, que não serão trabalhadas apenas com informações e sim em um contexto mais amplo, na formação do indivíduo objetivando mudanças de atitudes e comportamento.

\section{CONCLUSÃO}

Ao término da análise dos resultados, verificou - se que os sujeitos da pesquisa têm conhecimentos sobre HIV/AIDS, compatíveis com seu grau de escolaridade. Apesar disso, não o colocam em prática quando se considera esse para o uso de mecanismos de autoproteção, uma vez que o preservativo não é usado por todos.

O nível de informação sobre as vias de transmissão do HIV, não garante mudanças de comportamento.

No que se refere ao aumento do número de casos de HIV/AIDS em mulheres, verifica-se que o fato de ter um parceiro fixo, não tem sido garantia para não se adquirir a doença e um dos motivos apontados pelos entrevistados para o não uso do preservativo é ter um parceiro fixo ou estável ou ser casado. Desta forma, embora se diga que hoje em dia homens e mulheres têm direitos iguais, percebe-se que na prática do relacionamento sexual não é isto que acontece, principalmente quanto ao uso da camisinha, aumentando a vulnerabilidade feminina.

Outro motivo alegado para o não uso do preservativo, é que ele ainda é visto como algo que diminui a sensibilidade, interferindo negativamente no clima da relação.

Em relação às representações da palavra AIDS, embora muitos avanços tenham ocorrido no tratamento da doença, ela ainda significa medo e sofrimento para os jovens.

Muito já se avançou em termos do conhecimento da doença, do tratamento, da 
Cano MAT, Zaia JE, Neves FRA, Neves LAS. O conhecimento de jovens universitários sobre AIDS e sua prevenção. Revista Eletrônica de Enfermagem [serial on line] 2007 Set-Dez; 9(3): 748-758. Available from: URL: http://www.fen.ufg. br/revista/v9/n3/v9n3a14.htm

diminuição do preconceito, da eliminação da transmissão do vírus em transfusões, mas apesar disso, muito ainda se tem a fazer, temos um longo caminho pela frente.

\section{REFERÊNCI AS}

1. Brasil. Ministério da Saúde. Coordenação Nacional de DST e Aids. Guia de tratamento: recomendações para a profilaxia da transmissão vertical do HIV e terapia antiretoviral em gestantes. 4을 ed. Brasília: MS, 2007.

2. Queiroz AB. Diagnóstico do grau de conhecimento de contágio por HIV/AIDS das trabalhadoras do sexo nas zonas de prostituição de Franca-SP. Investigação 2002 set-dez; 4 (3): 188-196.

3. Guimarães CD. AIDS no feminino: porque a cada dia mais mulheres contraem AIDS no Brasil? Rio de Janeiro: Editora UFRJ; 2001. 231p.

4. Lima P, Durán VH. Gracias a la vida. Pesquisa FAPESP 2005 mai; (111).

5. Bastos FI, Szwarcwald CL. AIDS e pauperização: principais conceitos e evidências empíricas. Cadernos de Saúde Pública 2000; 16(supl. 1):53-64.

6. Reis RK, Gir E. Dificuldades enfrentadas pelos parceiros sorodiscordantes ao HIV na manutençao do sexo seguro. Rev. Latino-Am. Enfermagem 2005 fev; 13 (1):32-37.

7. Brasil. Ministério da Saúde. AIDS em números. [cited 2007 mai 20]. Available from: URL:

http://www.aids.gov.br/data/Pages/LUMIS13F4 BF21PTBRIE.htm.

8. Szwarcwald CL, Barbosa Jr.A, Pascom AR, Souza Jr. PRB. Pesquisa de conhecimento, atitudes e práticas na população brasileira de 15 a 54 anos - 2004. Boletim Epidemiológico 2004 jan-jun; I (1).

9. Carrazzone CFV, Brito AM de, Gomes YM. Importância da avaliação sorológica prétransfusional em receptores de sangue. Revista Brasileira de Hematologia e Hemoterapia, 2004; 26 (2): 93-98.

10. El Beitune P, Duarte G, Quintana SM. et al. Antiretroviral therapy during pregnancy and early neonatal life: consequences for HIVexposed, uninfected children. Braz J Infect Dis 2004 abr; 8 (2): 140-150.

11. Neves LA de S, Gir E. HIV positive mothers' beliefs about mother-to-child transmission. Rev. Latino-Am. Enfermagem 2006 oct; 14 (5): 781-788.
12. Neves FRAL. O aconselhamento para a realização da sorologia anti-HIV em gestantes: facilidade e Utopias 2003. 133p. Dissertação de Mestrado - Escola de Enfermagem de Ribeirão Preto, Universidade de são Paulo, Ribeirão Preto.

13. Guimarães R, Ferraz AF. A interface Aids, estigma e identidade - algumas considerações. Revista Mineira de Enfermagem 2002 jan-dez; 6 (1/2): 77-85.

14. Gir E, Vaichulonis CG, Oliveira MD. Adesão à terapêutica anti-retroviral por indivíduos com HIV/AIDS assistidos em uma instituição do interior paulista. Rev. Latino-Am. Enfermagem 2005 out; 13 (5): 634-641.

15. O ranking da AIDS. Revista Expressão 2006 jan; 9 (100). Ribeirão Preto.

16. Antunes MC, Peres CA, Paiva V, Stall R, Hearst N. Diferenças na prevenção da Aids entre homens e mulheres jovens de escolas públicas em São Paulo. Rev. Saúde Pública 2002; 36 (4): 88-95.

17. Oliveira A. Eles sabem tudo. Será? Revista Veja 2001 set; 34 (38):24-25. Edição Especial - Veja J ovem.

18. Petri V. AIDS e adolescência. In: Saito MI, Silva LEU. Adolescência: prevenção e risco: São Paulo: Atheneu, 2001.

19. Hebling EM, Guimarães IRF. Mulheres e aids: relações de gênero e $o$ uso do preservativo com parceiro estável. Cadernos de Saúde Pública 2004; 20 (5): 1211-1218.

20. Araújo MLM, Santos $R$, Mendes $A L$, Rodrigues LH, Canella PRB. Saber sobre a importância do uso do preservativo influencia o seu uso? Reprodução \& Climatério 2002; 17 (1):25-29.

Artigo recebido em 15.01.07

Aprovado para publicação em 10.12.07 